\title{
Modeling the Effects of Hydrated Lime Additives on Asphalt Mixtures by Fuzzy Logic and ANN
}

\author{
Mustafa Sinan YARDIM ${ }^{1}$ \\ Betül DEĞER ŞITILBAY² \\ Selim DÜNDAR ${ }^{3}$
}

\begin{abstract}
In this study, Marshall design test parameters of hot mix asphalt samples with various rates of Hydrated Lime (HL) content were modelled using Fuzzy Logic (FL) and Artificial Neural Networks (ANN). HL was used as an additive material in asphalt mixtures and it affects the properties of the mixture. The effect of this material varies depending on the rate of use and the asphalt content of the mixtures. With the Marshall Stability test, optimal Asphalt Content (AC) ratios in the mixtures were obtained. The effect of the HL additive, which was introduced precisely in the mixtures in a wide range, on the Marshall parameters and depending also on the asphalt content was investigated. For this purpose, 15 Marshall design sets were prepared by decreasing the ratio of the mineral filler in the mixture starting from $6.8 \%$ by weight, by $0.5 \%$ intervals, and replacing it with the same ratio of HL. In addition, 45 control samples were produced for soft-computation. Marshall test results showed that the use of HL additive with lower amounts in the mixtures yields better results compared to higher rates in terms of the material properties. The Marshall test results were used to develop the FL and ANN models. The models which were developed produced acceptable estimations of the mixture parameters.
\end{abstract}

Keywords: Hot mix asphalt, hydrated lime, Marshall mix design, fuzzy logic, artificial neural networks.

\section{INTRODUCTION}

Deformations in flexible pavements are amongst the most important problems encountered in highway construction and operation. The main reasons for the deformations are excessive

Note:

- This paper has been received on March 07, 2018 and accepted for publication by the Editorial Board on January 28, 2019.

- Discussions on this paper will be accepted by January 31, 2020.

- https://dx.doi.org/10.18400/tekderg.402816

1 Yıldız Technical University, Department of Civil Engineering, İstanbul, Turkey - yardim@yildiz.edu.tr https://orcid.org/0000-0003-0799-9294

2 Yıldız Technical University, Department of Civil Engineering, İstanbul, Turkey - bdeger@yildiz.edu.tr https://orcid.org/0000-0003-0723-9789

3 İstanbul Okan University, Dep. of Civil Engineering, İstanbul, Turkey - selim.dundar@okan.edu.tr https://orcid.org/0000-0003-4433-1998 
traffic loads and environmental conditions such as the temperature change or exposure to water. These factors shorten the service life of the highways which is undesirable for both the users and administrators of the highways. Several methods have been implemented in order to prevent and control various deformations in flexible pavements. One method is to modify the bituminous mixtures used in the pavements. Various additives can be used for the modification process. Either the aggregate or the bitumen in the mixture can be modified according to the deformation problem encountered.

The use of hydrated lime (HL) in the modification of hot mix asphalt has an important place in the solution of problems encountered in pavements. There are many studies in the literature to determine the positive and negative effects of HL in mixtures [1,2]. Not only the type, but also the amount of the additive, has an effect on the mixture. In this study, the filler amount has been gradually decreased in the mixture by substituting it with HL. In order to see the gradual effect of the HL, the changes are made in small percentage intervals. The Marshall Stability Test was applied to the samples which were prepared in accordance with standards [3]. Optimal Asphalt Content (AC) and the parameters that define the properties of the mixture (unit weight or practical specific weight (Dp), void filled with asphalt (VFA), Marshall Stability (MS), air voids (Va), voids in mineral aggregate (VMA), flow rate (F) and Marshall Quotient (MQ)) for each HL content have been obtained as a result of the tests. Practically speaking, estimation of the mixture parameters from the AC and HL percentages using soft computing methods is useful to obtain fast and realistic results to aid the decision making processes. In this study, FL and ANN models have been developed to estimate the mixture parameters from the AC and HL percentages introduced.

\section{BACKGROUND}

Bitumen mixtures have to provide the desired performance during their service life. The main physical and mechanical properties of bitumen mixtures are stability, durability, flexibility, resistance to fatigue and creep, impermeability and workability [4]. Many studies have been carried out to improve these properties. One of these methods is the usage of HL as an additive. Lime, which decreases both the moisture sensitivity and stripping, has been used as an additive in the US since 1910. Although HL has been recognized for its antistripping feature, recently other benefits have also been discovered. Resistance to wheel track formation, resistance to enlarging of low temperature cracks, increasing the rigidity, altering the oxidation properties of the binder, decreasing the aging stiffening, adjusting the moisture and increasing the stability by modifying the clay grains can be listed amongst them [1]. The main problems of hot mix asphalt pavements that are affected by the rheological properties of asphalt are stripping, deterioration and cracking [5]. Especially, some aggregate types have a tendency to strip. Temperature, heavy rainfall, freeze-thaw cycle and traffic loads have a great impact on the stripping feature. HL is the most effective stripping-preventive additive and is widely used for this purpose $[1,6,7]$. HL decreases the failure risk of the asphaltaggregate bond mechanically and has a positive effect on this problem even with lack of water in the environment $[1,6]$. HL increases the tensile strength of the pavements [8,9] by increasing the elasticity modulus of the mixture $[10,11]$. It especially increases the strength by helping dispersion of the strains caused by traffic loads [12]. [13-20] remark on the significant effect of HL on the decrement of permanent deformations. This effect helps to improve the stiffening properties and to resist wheel track formations [15, 21-22]. HL alters 
the oxidation properties of the binder [23], decreases ageing stiffening [15, 16, 24-26] and increases ageing performance [27-32]. As moisture damage decreases the effective life period of the pavement by damaging its integrity, usage of HL increases the pavement life [33] up to 38\% [34]. Various benefits of HL usage on hot mix asphalt have been reported under specific conditions (the type, origin and gradation of the aggregate used; the type, properties and amount of the binder; the type, amount, property and usage type of other additives; climate and temperature changes, project service life; and pavement load conditions, etc.); in this context, $\mathrm{HL}$ is defined as a multi-functional additive $[1,26,35]$.

In this study, FL and ANN models that estimate the Marshall test results from given AC and HL ratios have been developed. Soft computing methods are widely used in the literature on modeling hot mix asphalt properties. [36] used the Fuzzy Logic (FL) approach on investigating the fatigue behavior of asphalt concrete pavements. Fatigue life has been estimated by a fuzzy algorithm taking deformation measurements into account. [37] modeled the deflection behavior of flexible pavements under dynamic loading using FL. FL provided better modeling performance than linear elastic theory and finite element methods. [38] developed an ANN that uses experimental results and finite element method outputs to model the behavior of the free material in the sub-base layer of flexible pavements. The proposed approach was considered suitable for realistic solutions of back-calculation problems. [39] used ANN on modeling emulsified asphalt mixtures. Curing time, cement addition level, and residual asphalt content were used as the input, and the flexibility modulus was used as the output parameters of the model. The development of a 3-layered back propagating ANN provided good results on estimating the flexibility modulus. [40] modeled the Marshall Stability of hot mix asphalt samples exposed to various temperatures under various times. [41] developed an ANN to model the long term aging of the bitumen binder. ANN had better performance and easier usage than the regression models. [42] used artificial intelligence methods to analyze permanent deformations of asphalt mixtures and to investigate the wheel track potential of dense asphalt-aggregate mixtures. Multi Expression Programming (MEP)based straightforward formulas have been developed which are easy tools to use in various engineering applications. ANN have also been used to estimate the results of repeated creep tests [43] and Marshall Stability, flow rate and Marshall Quotient [44] for Polypropylene (PP) modified asphalt mixtures. The physical properties of the asphalt mixture, such as the PP type, PP ratio, AC, sample height, unit weight, VMA, VFA and air voids have been used. [45] used ANN to estimate the rigidity behavior of reclaimed asphalt pavements having rubberized asphalt concrete. ANN performed better than the regression model to estimate the fatigue life of the modified mixtures. ANN are also used to determine the complex modulus of Styrene Butadiene Styrene (SBS) modified bitumen. The bitumen heat, frequency and SBS content [46] and mixing heat, rate, time, experiment temperature and frequency [47] were used as the inputs of the ANN model to determine the complex modulus of SBS modified bitumen. [48] developed two genetic algorithms (GA) to determine the damping ratio and shear modulus of sand-mica mixtures. The mica content and effective stress and strain values were used to determine the damping ratio and shear modulus. A good correlation $\left(\mathrm{R}^{2}=0.95\right)$ was established between the developed model and the test results. [49] developed a heuristic $\mathrm{k}$ Nearest Neighbor ( $\mathrm{k}-\mathrm{NN}$ ) estimator based on genetic programming to model Marshall Stability test data of asphalt mixtures. The model estimated the Marshall parameters with high accuracy. [50] developed an Adaptive Neuro-Fuzzy Inference System (ANFIS) to determine the wheel track of Polyethylene Terephthalate (PET) modified asphalt mixtures. 
PET content, strain levels and test temperatures were used as the input parameters. Comparison with test results proved that ANFIS can be an effective estimation method. [51] simulated the elasticity modulus of hot mix asphalts containing Recycled Concrete Aggregates (RCA) and stone mastic asphalt mixtures using ANFIS. RCA content and test temperatures were used as the input parameters. ANFIS supplied the best results for mixed RCA while the most erroneous results were obtained for coarse RCA when compared with the test results.

\section{EXPERIMENTAL STUDY}

\subsection{Material Properties}

In this study, the aggregates used were provided from İsfalt A. Ş. Ümraniye Asphalt Plant. The source of this material is the limestone quarries of Ömerli, Istanbul, located in the northwestern part of Turkey. $\mathrm{CaO}$, of $52.9 \%$ content, comprises the main oxide element of the limestone of this region and $75 \%$ of the mineralogical composition is calcite. The limestone used for the production has a grey to dark grey color [52]. No. 2, No. 1 and stone powder aggregates were washed, dried and sifted on 3/4", 1/2", 3/8", No. 4, No. 10, No. 40, No. 80 and No. 200 sieves of the shaking machine in accordance with the standards [53]. Weight of the material passing from each sieve was calculated and its distribution was determined according to the Wearing Course Type-1 mixture ratios of the Highway Technical Specifications of the General Directorate of Turkish Highways (Karayolları Genel Müdürlüğü - KGM) [54]. In this study, aggregate No. 2 was taken at 15\%, No. 1 at 40\% and the stone powder at $45 \%$. The coarse and fine aggregates and mineral filler material had ratios of $51.3 \%, 41.9 \%$ and $6.8 \%$, respectively in the mixture. This aggregate mixture was dense, in other words it was well-graded. The properties of the aggregate are given in Table 1 while the gradation curve of the aggregate mixture is given in Figure 1.

Table 1 - Physical properties of aggregates

\begin{tabular}{lccc} 
Aggregate Type & $\begin{array}{c}\text { Apparent Specific } \\
\text { Gravity } \mathbf{( g / \mathbf { c m } ^ { 3 } )}\end{array}$ & $\begin{array}{c}\text { Bulk Specific Gravity } \\
\left(\mathbf{g} / \mathbf{c m}^{\mathbf{3}}\right)\end{array}$ & $\begin{array}{c}\text { Water } \\
\text { Absorption (\%) }\end{array}$ \\
\hline Coarse Aggregate & 2.729 & 2.698 & 0.42 \\
\hline Fine Aggregate & 2.754 & 2.693 & 0.82 \\
\hline Mineral Filler & 2.735 & - & - \\
\hline Aggregate Mixture & 2.740 & 2.699 & -
\end{tabular}

50/70 penetration bitumen provided from İzmit Oil Refinery (Tüpraş) was used as the asphalt cement. The properties and criteria of this binder were obtained using the tests applied as shown in Table 2. Optimum AC was determined for different HL content using the Marshall method. For this reason, 3 samples were prepared for each $\mathrm{AC}$, varying between $4.0 \%$ and $6.5 \%$, with $0.5 \%$ intervals, comprising a total of 18 sample sets. 


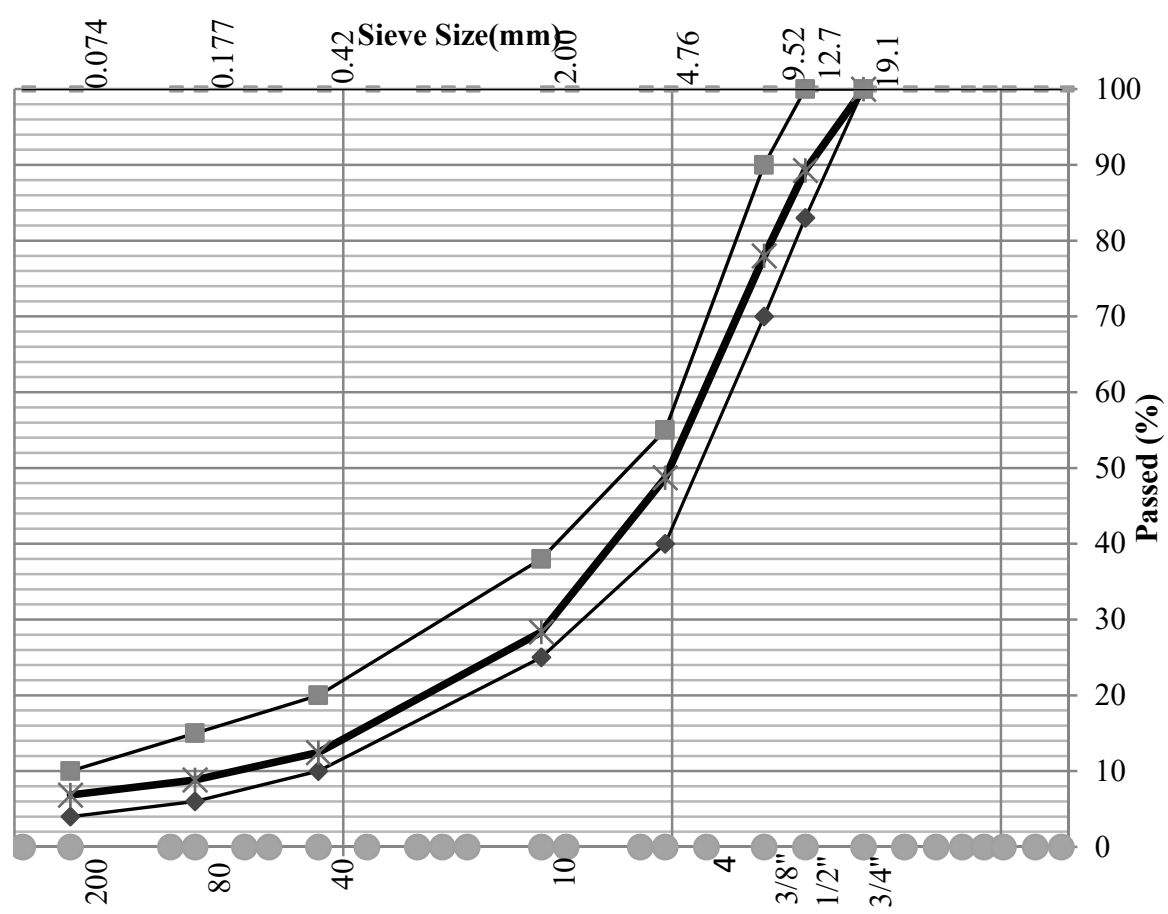

Figure 1 - Aggregate gradation curve

Table 2 - Physical properties of the bitumen

\begin{tabular}{lccc} 
Properties & Standards & $\begin{array}{c}\text { Test } \\
\text { Value }\end{array}$ & Specification \\
\hline Specific gravity $\left(\mathrm{g} / \mathrm{cm}^{3}\right)$, at $25^{\circ} \mathrm{C}$ & ASTM D 70 & 1.009 & - \\
Flash point $(\mathrm{Cleveland})\left({ }^{\circ} \mathrm{C}\right)$ & ASTM D 92 & 345 & $>230$ \\
Penetration $(0.1 \mathrm{~mm})$, at $25^{\circ} \mathrm{C}, 100 \mathrm{~g}, 5 \mathrm{sec}$ & ASTM D 5 & 59.80 & $50-70$ \\
Ductility $(\mathrm{cm})$, at $25^{\circ} \mathrm{C}, 5 \mathrm{~cm} / \mathrm{min}$ & ASTM D 113 & $>100$ & $>100$ \\
Thin film heating loss $(\%)$, at $163{ }^{\circ} \mathrm{C}, 5 \mathrm{hr}$ & ASTM D 1754 & 11 & $<80$ \\
Penetration percentage after heating loss $(\%)$ & ASTM D 5 & 65.90 & $>54$ \\
Ductility after heating loss $(\mathrm{cm})$ & ASTM D 113 & 65.40 & $>50$ \\
Softening point $\left({ }^{\circ} \mathrm{C}\right)$ & ASTM D 36 & 48.50 & $45-55$
\end{tabular}

In this study, the mineral filler material percentage of the aggregate mixture with a determined gradation was decreased gradually, and replaced with the same amount of HL. The additive used in the experiment was the powdered calcium lime, produced with the code S-KK 80-T at the 
Bartın Lime Factory which is located in northern Turkey. The properties of this material which also has one of the lowest densities in the Turkish market, are given in Table 3.

\section{Table 3 - Properties of hydrated lime}

\begin{tabular}{|c|c|c|c|}
\hline Properties & Standards & Test Value & Specification \\
\hline \multicolumn{4}{|l|}{ Chemical Properties } \\
\hline Total $\mathrm{CaO}(\%)$ & $\begin{array}{l}\text { TS EN 459-1 } \\
\text { TS } 32 \text { EN 459-2 }\end{array}$ & 85.78 & $>80$ \\
\hline $\mathrm{MgO}(\%)$ & $\begin{array}{l}\text { TS EN 459-1 } \\
\text { TS } 32 \text { EN 459-2 }\end{array}$ & 3.52 & $<5$ \\
\hline Total $\mathrm{CaO}+\mathrm{MgO}(\%)$ & TS EN 459-1 & 89.30 & $>80$ \\
\hline Loss on Ignition (\%) & TS 32 EN 459-2 & 22.51 & \\
\hline $\mathrm{SO}_{3}(\%)$ & $\begin{array}{l}\text { TS EN 459-1 } \\
\text { TS } 32 \text { EN 459-2 }\end{array}$ & 1.47 & $<2.00$ \\
\hline $\mathrm{CO}_{2}(\%)$ & $\begin{array}{l}\text { TS EN 459-1 } \\
\text { TS } 32 \text { EN 459-2 }\end{array}$ & 3.89 & $<7.00$ \\
\hline \multicolumn{4}{|l|}{ Physical Properties } \\
\hline Fineness over 90 microns (\%) & $\begin{array}{l}\text { TS EN 459-1 } \\
\text { TS } 32 \text { EN 459-2 }\end{array}$ & 6.00 & $<9.00$ \\
\hline Density $\left(\mathrm{kg} / \mathrm{m}^{3}\right)$ & TS 32 EN 459-2 & 472 & $<600$ \\
\hline
\end{tabular}

\subsection{Preparation of the Mixtures and the Marshall Test}

In this study, to determine the effect of each HL ratio, the mineral filler material content of the mixture was decreased with intervals of $0.5 \%$, and replaced with the HL, in order to prepare various designs. In other words, a different design, in line with the Marshall Method $[55,56]$, was prepared for each HL ratio, to determine the optimum AC ratio. Three samples for each of the $6 \mathrm{AC}$ values ( $2 \times 50$ strokes were applied on two sides) were produced for each of the 15 different HL ratios and properties of each sample were determined [57].

15 different HL ratios were used in the developed model. In order to determine the optimum amount of AC for each different HL ratio, Marshall designs were prepared using 6 different ACs. (In traditional Marshall design methods, curves with $3^{\text {rd }}$ degree equations produce high precision levels. Thus, the relation between the Marshall parameters and the AC were defined as $3^{\text {rd }}$ degree curves). Three samples were prepared for each HL-AC pair and the arithmetic mean of the results obtained from the analyses was used in the model. For this reason, 90 data were obtained from the 270 samples in the model. The samples produced were used to develop, train, validate and test the FL and ANN models as will be seen in the following sections. The Marshall designs for different amounts of HL, the optimum AC obtained, and the associated parameters are summarized in Table 4. Also, the apparent specific gravity values of the sum of the mineral filler and HL (Gsa) are added into the third column of the table. 
Table 4 - Marshall Test results for different HL content

\begin{tabular}{|c|c|c|c|c|c|c|c|c|c|c|}
\hline \multirow{2}{*}{ 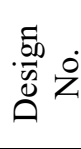 } & $\begin{array}{c}\text { HL } \\
\text { Cont. }\end{array}$ & Gsa & $\begin{array}{l}\text { Opt. } \\
\text { AC }\end{array}$ & $\mathrm{Dp}$ & VFA & MS & $\mathrm{Va}$ & $\mathrm{F}$ & VMA & \multirow{2}{*}{$\begin{array}{c}\text { MQ } \\
(\mathrm{MS} / \mathrm{F})\end{array}$} \\
\hline & $(\%)$ & $\left(\mathrm{g} / \mathrm{cm}^{3}\right)$ & $(\%)$ & $\left(\mathrm{g} / \mathrm{cm}^{3}\right)$ & $(\%)$ & $(\mathrm{kN})$ & $(\%)$ & $\mathrm{mm}$ & $(\%)$ & \\
\hline 1 & 0.0 & 2.806 & 5.20 & 2.409 & 73.0 & 11.6 & 4.10 & 4.4 & 15.27 & 2.64 \\
\hline 2 & 0.5 & 2.776 & 5.28 & 2.398 & 71.6 & 11.64 & 4.45 & 4.85 & 15.70 & 2.40 \\
\hline 3 & 1.0 & 2.760 & 5.25 & 2.400 & 72.0 & 11.60 & 4.40 & 4.75 & 15.58 & 2.44 \\
\hline 4 & 1.5 & 2.702 & 5.47 & 2.371 & 68.9 & 8.58 & 5.18 & 4.13 & 16.63 & 2.08 \\
\hline 5 & 2.0 & 2.519 & 5.35 & 2.387 & 72.9 & 9.81 & 4.09 & 4.20 & 15.55 & 2.34 \\
\hline 6 & 2.5 & 2.588 & 5.59 & 2.372 & 71.6 & 8.41 & 4.62 & 4.40 & 16.29 & 1.91 \\
\hline 7 & 3.0 & 2.609 & 5.38 & 2.377 & 70.05 & 9.25 & 4.80 & 6.05 & 16.20 & 1.53 \\
\hline 8 & 3.5 & 2.586 & 5.60 & 2.374 & 72.0 & 8.75 & 4.50 & 4.27 & 16.26 & 2.05 \\
\hline 9 & 4.0 & 2.571 & 5.39 & 2.371 & 70.03 & 10.24 & 4.84 & 4.55 & 16.25 & 2.25 \\
\hline 10 & 4.5 & 2.505 & 5.54 & 2.355 & 69.0 & 8.70 & 5.18 & 4.10 & 16.65 & 2.12 \\
\hline 11 & 5.0 & 2.448 & 6.16 & 2.342 & 73.0 & 8.41 & 4.80 & 5.10 & 17.32 & 1.65 \\
\hline 12 & 5.5 & 2.544 & 6.33 & 2.358 & 76.5 & 8.05 & 4.20 & 5.40 & 17.44 & 1.49 \\
\hline 13 & 6.0 & 2.501 & 6.23 & 2.366 & 77.0 & 8.30 & 3.80 & 6.52 & 16.78 & 1.27 \\
\hline 14 & 6.5 & 2.488 & 5.74 & 2.324 & 66.0 & 8.12 & 6.10 & 4.11 & 17.94 & 1.98 \\
\hline 15 & 6.8 & 2.419 & 6.10 & 2.350 & 74.0 & 8.70 & 4.42 & 4.60 & 17.04 & 1.89 \\
\hline
\end{tabular}

Table 5 - Marshall Test results for control production samples (CPS)

\begin{tabular}{|c|c|c|c|c|c|c|c|c|c|}
\hline \multirow{2}{*}{ 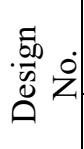 } & $\begin{array}{c}\text { HL } \\
\text { Cont. }\end{array}$ & $\begin{array}{l}\text { Opt. } \\
\text { AC }\end{array}$ & $\mathrm{Dp}$ & VFA & MS & $\mathrm{Va}$ & $\mathrm{F}$ & VMA & \multirow{2}{*}{$\begin{array}{c}\text { MQ } \\
(\mathrm{MS} / \mathrm{F})\end{array}$} \\
\hline & $(\%)$ & $(\%)$ & $\left(\mathrm{g} / \mathrm{cm}^{3}\right)$ & $(\%)$ & $(\mathrm{kN})$ & $(\%)$ & $\mathrm{mm}$ & $(\%)$ & \\
\hline 1 & 0.0 & 5.20 & 2.403 & 71.72 & 11.35 & 4.38 & 6.57 & 15.50 & 1.73 \\
\hline 2 & 0.5 & 5.28 & 2.369 & 66.64 & 9.79 & 5.57 & 4.73 & 16.70 & 2.07 \\
\hline 3 & 1.0 & 5.25 & 2.365 & 65.77 & 8.89 & 5.75 & 4.55 & 16.79 & 1.96 \\
\hline 4 & 1.5 & 5.47 & 2.356 & 66.78 & 8.33 & 5.70 & 3.99 & 17.17 & 2.09 \\
\hline 5 & 2.0 & 5.35 & 2.370 & 69.93 & 9.56 & 4.85 & 4.28 & 16.14 & 2.23 \\
\hline 6 & 2.5 & 5.59 & 2.367 & 70.94 & 8.63 & 4.82 & 3.84 & 16.60 & 2.24 \\
\hline 7 & 3.0 & 5.38 & 2.348 & 65.47 & 8.69 & 5.93 & 3.86 & 17.17 & 2.25 \\
\hline 8 & 3.5 & 5.60 & 2.340 & 66.35 & 7.43 & 5.91 & 4.03 & 17.57 & 1.84 \\
\hline 9 & 4.0 & 5.39 & 2.357 & 67.43 & 10.08 & 5.46 & 4.08 & 16.77 & 2.47 \\
\hline
\end{tabular}


Modelling the Effects of Hydrated Lime Additives on Asphalt Mixtures by ...

Table 5 - Marshall Test results for control production samples (CPS) (continued)

\begin{tabular}{|c|c|c|c|c|c|c|c|c|c|}
\hline \multirow{2}{*}{$\begin{array}{l}\frac{\tilde{D 0}}{\tilde{N}} \\
\stackrel{0}{0}\end{array}$} & $\begin{array}{c}\text { HL } \\
\text { Cont. }\end{array}$ & $\begin{array}{c}\text { Opt. } \\
\text { AC }\end{array}$ & $\mathrm{Dp}$ & VFA & MS & $\mathrm{Va}$ & $\mathrm{F}$ & VMA & \multirow{2}{*}{$\begin{array}{c}\text { MQ } \\
(\mathrm{MS} / \mathrm{F})\end{array}$} \\
\hline & $(\%)$ & $(\%)$ & $\left(\mathrm{g} / \mathrm{cm}^{3}\right)$ & $(\%)$ & $(\mathrm{kN})$ & $(\%)$ & $\mathrm{mm}$ & $(\%)$ & \\
\hline 10 & 4.5 & 5.54 & 2.352 & 68.51 & 9.76 & 5.33 & 5.28 & 16.92 & 1.85 \\
\hline 11 & 5.0 & 6.16 & 2.354 & 75.06 & 8.73 & 4.29 & 5.83 & 17.18 & 1.50 \\
\hline 12 & 5.5 & 6.33 & 2.362 & 76.99 & 8.17 & 3.97 & 4.54 & 17.27 & 1.80 \\
\hline 13 & 6.0 & 6.23 & 2.368 & 77.77 & 8.67 & 3.75 & 4.61 & 16.87 & 1.88 \\
\hline 14 & 6.5 & 5.74 & 2.319 & 65.08 & 8.12 & 6.36 & 3.88 & 18.20 & 2.09 \\
\hline 15 & 6.8 & 6.10 & 2.338 & 71.94 & 8.52 & 4.95 & 4.20 & 17.63 & 2.03 \\
\hline
\end{tabular}

In addition, three different samples with optimum $\mathrm{AC}$ for each of the 15 different HL ratios were produced, consisting of a total of 45 new samples. The Dp values of these Control Production Samples (CPS) were obtained during the sample preparation stage while MS and $F$ values were obtained by testing of the Marshall device (Table 5). The values of the other parameters, namely Va, VMA and VFA were obtained as a result of the calculations used in the Marshall design method [55, 56].

The results of this sample set were used in re-testing the validity of the FL and ANN models. Also, the Dp, MS, Va, VFA, VMA, F and MQ values for each optimum AC were obtained from their respective 3rd degree curves and defined as the mathematical model results.

\section{FL MODEL}

In this study, each of the input parameters (AC and $\mathrm{HL}$ ) and the output parameters (Dp, VFA, MS, Va, VMA, F and MQ) of the FL model are defined with 3 membership functions as "low", "medium" and "high". It was considered that the input parameters might not have the same impact on each of the 7 properties of the asphalt samples. In other words, for example, when estimating the MS of the sample, the values of the HL between 3 and 5 can be considered as medium, but when estimating the flow rate the limits of a medium set can be between 2 and 4.5. Therefore, instead of developing a single FL model to estimate the value of the 7 output parameters, 7 separate FL models were developed to estimate each one. Thus, the values of each parameter were estimated with higher precision. The following steps were carried out while developing the FL models:

(a) Fuzzification: First of all, the input and output parameters of each model were fuzzified. In order to develop the simplest models, input and output parameters were divided into 3 fuzzy sets as "low", "medium" and "high" and the triangular membership functions seen in Figure 2 were used to define them. Also, the usage of 3 fuzzy sets defines the rule base with the minimum number of rules. The triangular membership functions are defined with 3 critical points, namely the start (a), the peak (b) and the end (c) points. Points a and c correspond to the membership function value of 0 , while $\mathrm{b}$ corresponds to the value of 1 . 


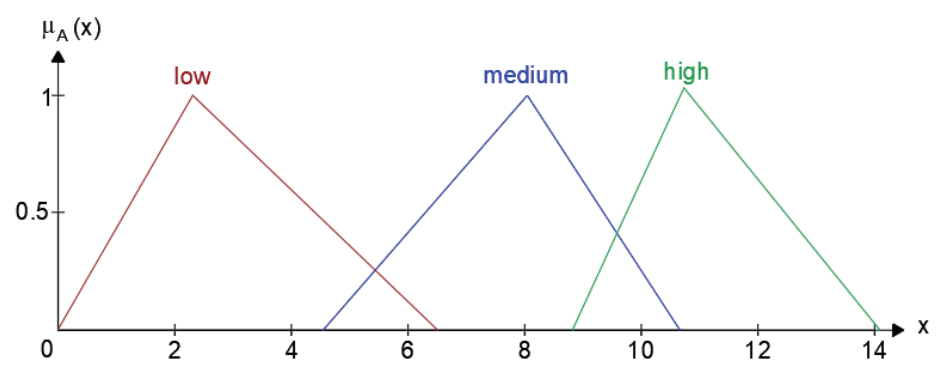

Figure 2 - Membership functions

(b) Generation of the Rule Base: In order to generate the initial rule base, 3D graphics were drawn which show the change of the output values according to the change in input values (Figures 3-9). By using the graphics, rules formed from 2 inputs and a single output parameter were generated. The rules defining the relation between input and output parameters are defined as:

$R_{1}$ IF AC is A(1) AND SK is B(1) THEN output is C(1)

$R_{2}$ IF AC is A(2) AND SK is B(1) THEN output is C(2)

Also

$R_{N}$ : IF AC is $A(n)$ AND SK is $B(n)$ THEN output is $C(n)$

Here $\mathrm{n}=3, \mathrm{~N}=3 \times 3=9, \mathrm{~A}(1), \mathrm{A}(2), \mathrm{A}(3)$ and $\mathrm{B}(1), \mathrm{B}(2), \mathrm{B}(3)$ represent the fuzzy sets of input parameters while $C(1), C(2), C(3)$ represent the fuzzy sets of the output parameters.

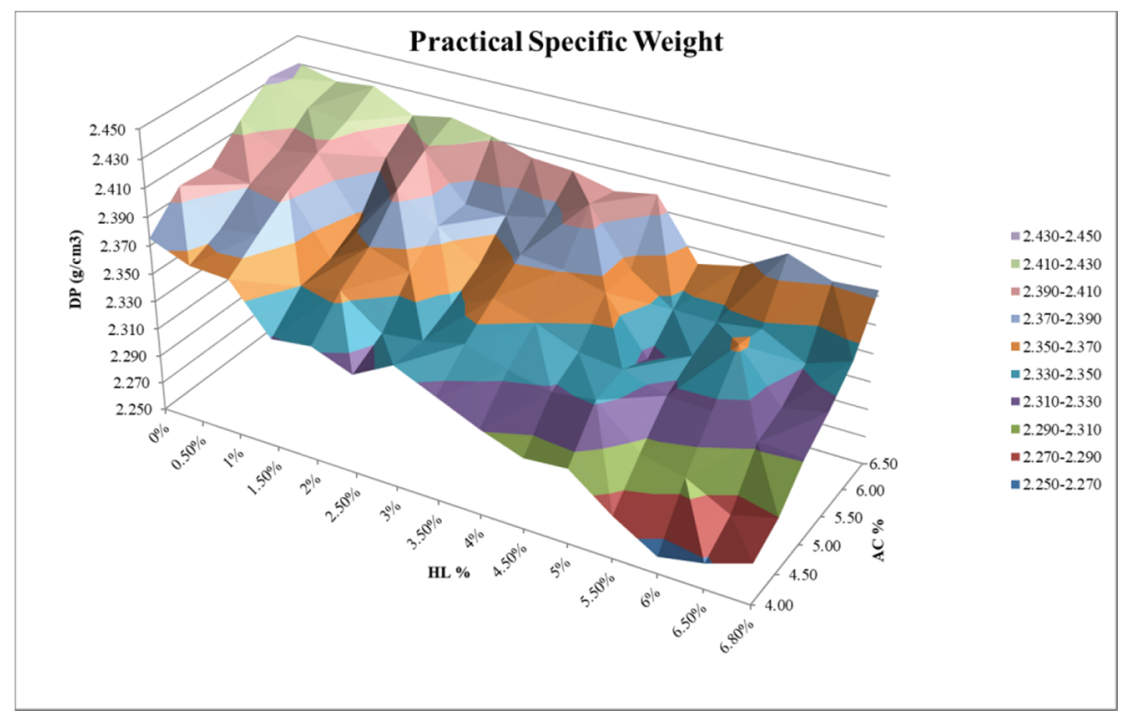

Figure 3 - Change of unit weight according to the change in HL and AC 
Modelling the Effects of Hydrated Lime Additives on Asphalt Mixtures by ...

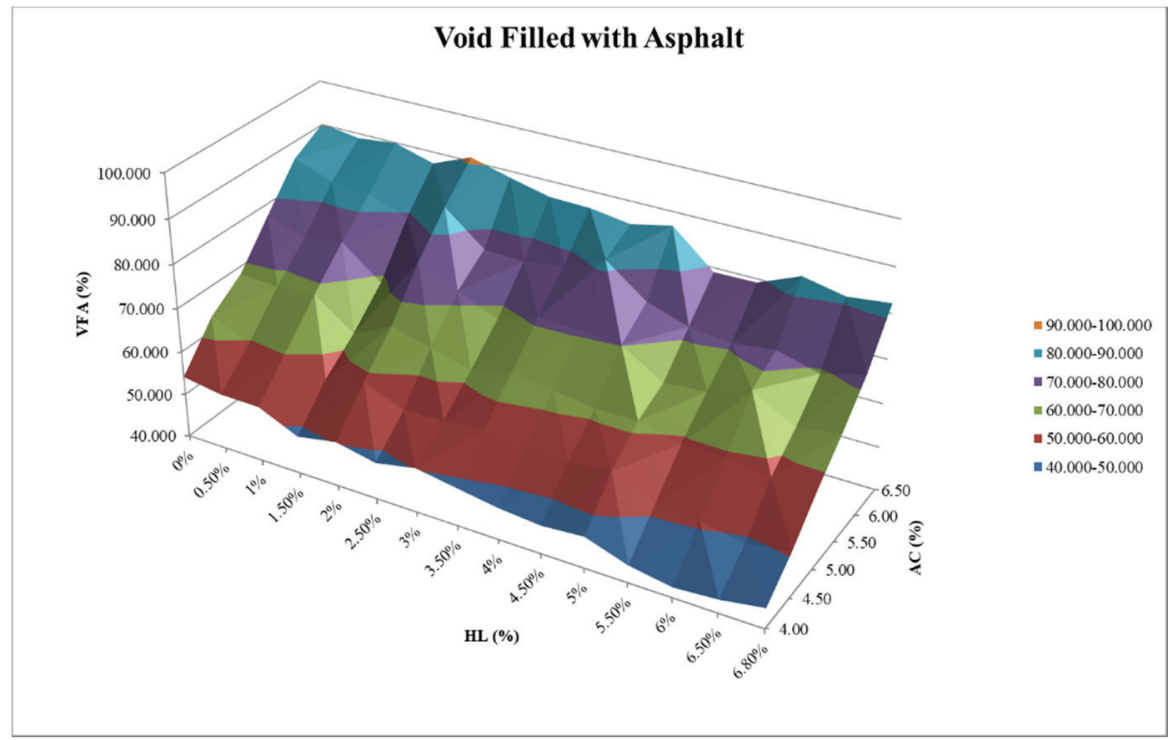

Figure 4 - Change of VFA according to the change in HL and AC

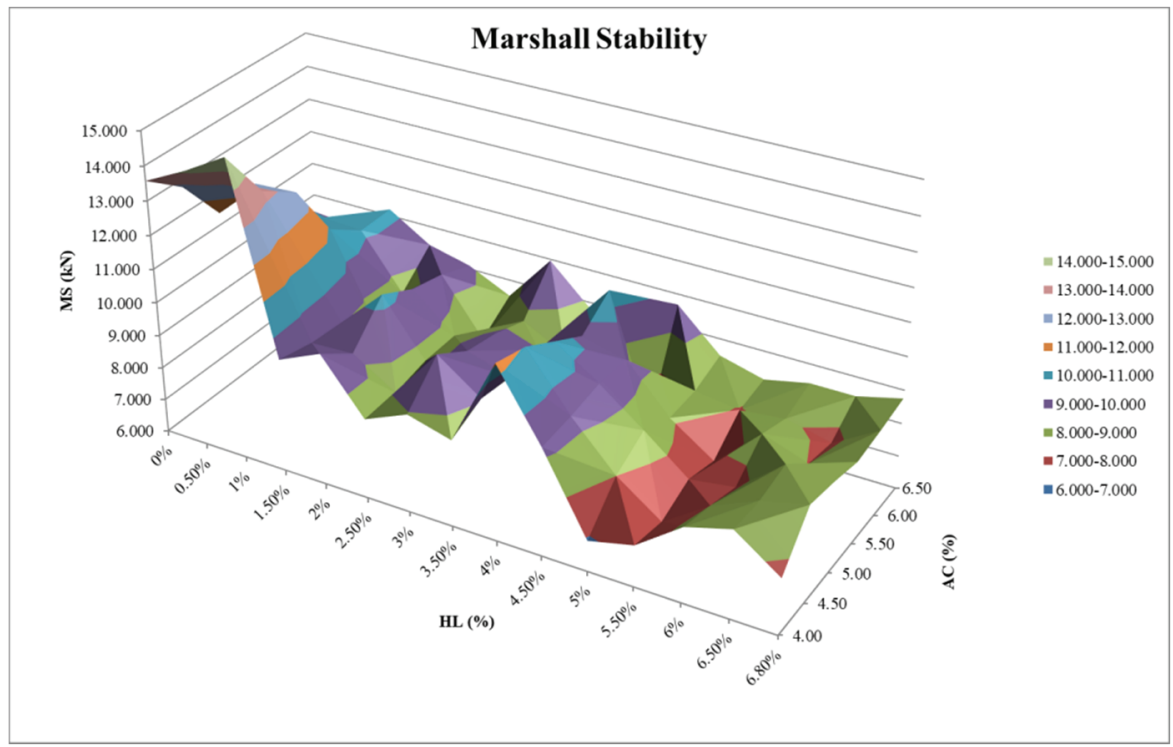

Figure 5 - Change of Marshall stability according to the change in HL and AC 


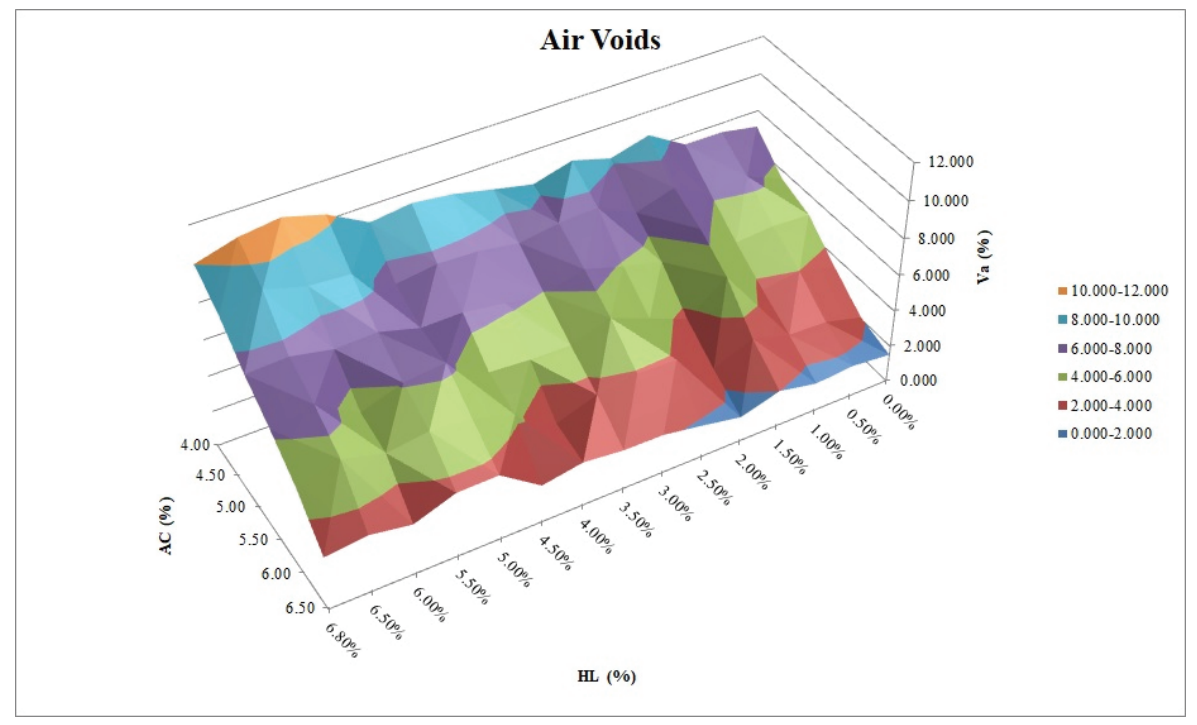

Figure 6 - Change of air voids according to the change in $H L$ and $A C$

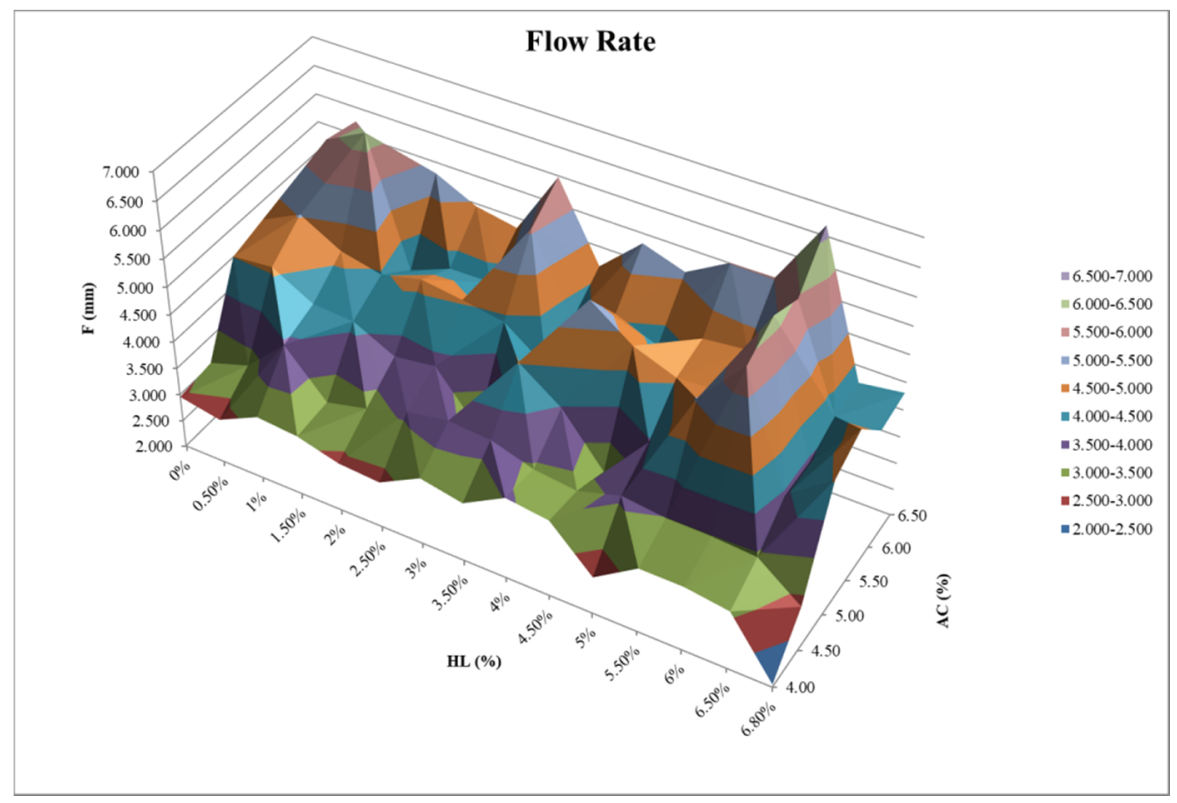

Figure 7 - Change of flow rate according to the change in $H L$ and $A C$ 
Modelling the Effects of Hydrated Lime Additives on Asphalt Mixtures by ...

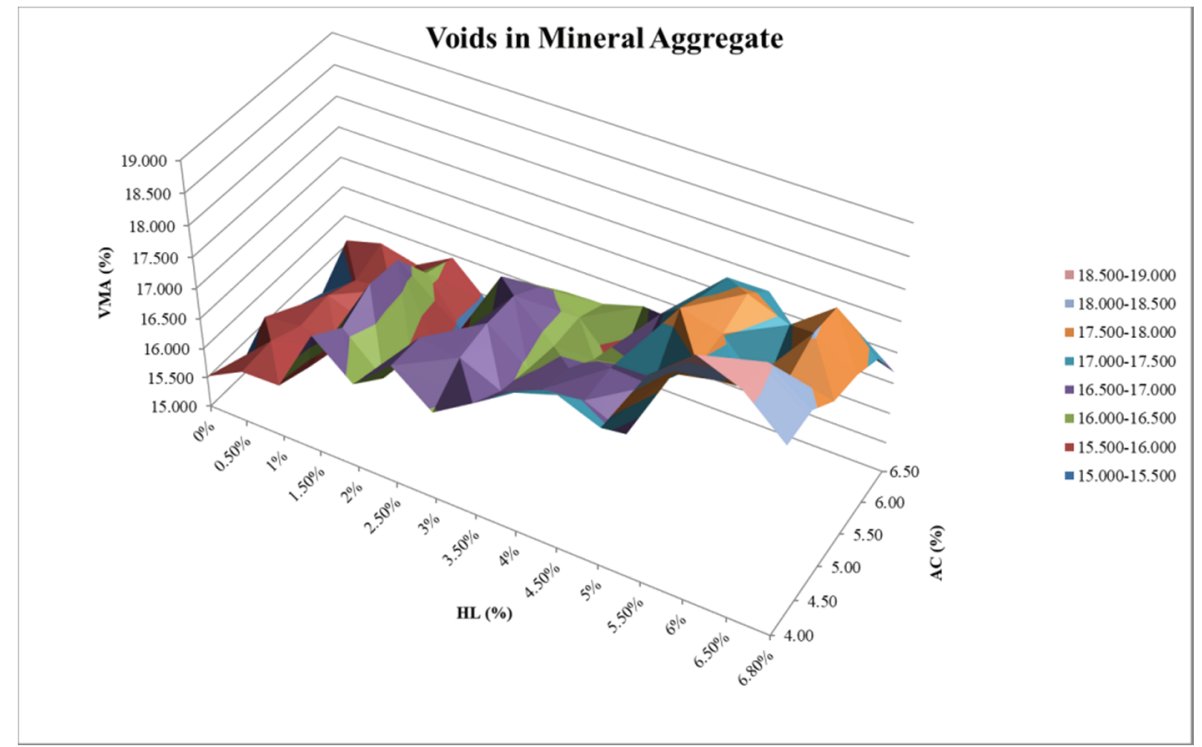

Figure 8 - Change of voids in mineral aggregate according to the change in HL and AC

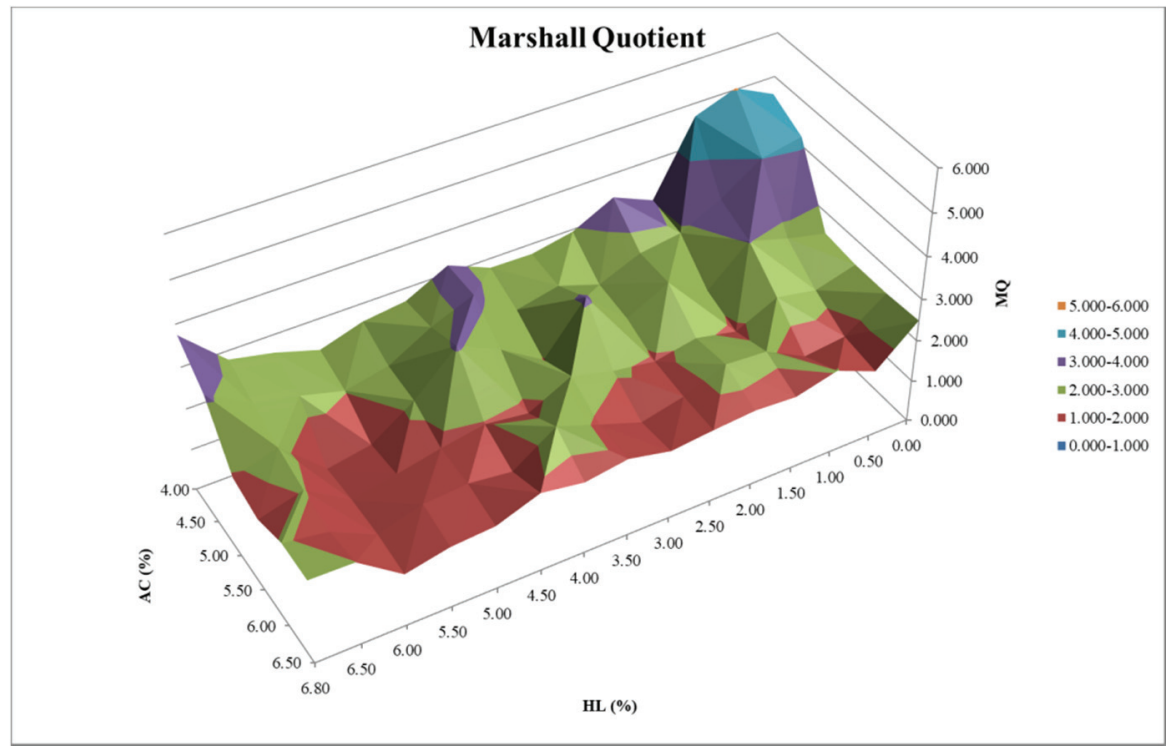

Figure 9 - Change of Marshall quotient according to the change in HL and AC 
(c) Defuzzification: Each input and output value activates one or more of the rules of the rule base. Various membership function graphics are obtained by the superposition of the activated output functions. In the defuzzification process, a single value is extracted from the graphics obtained. A number of methods can be used in defuzzification. In this study, the center of gravity method was preferred due to its simplicity. In this method, the abscissa of the center of gravity of the obtained figure is taken as the output value. [58] defines this value as:

$$
\bar{x}_{0}(A)=\frac{\int_{a}^{c} x \mu_{A}(x) d x}{\int_{a}^{c} \mu_{A}(x) d x}
$$

Here, $\bar{x}_{0}(A)$ represents the projection of the figure on the horizontal axis, a and c represent the abscissa of the start and end points of the figure, respectively and $\mu_{A}$ represents the membership function of $A$.

(d) Calibration: In this study, a GA optimizes the rule base as well as the membership functions, avoiding the risk of using incorrectly defined rules.

Each chromosome that represents the individuals of the GA is comprised of 36 genes as seen in Figure 10. Genes 1-9, 10-18 and 19-27 are values that represent the critical points of the fuzzy sets of the AC, HL and output parameter, respectively. The first 3 critical points represent the "low", the second 3 represent the "medium" and the last 3 represent the "high" for the start, peak and end points of the set of each parameter. Genes 28-36 represent the 9 rules located in the rule base and take the values of 1, 2 or 3 representing "low", "medium" and "high", respectively.

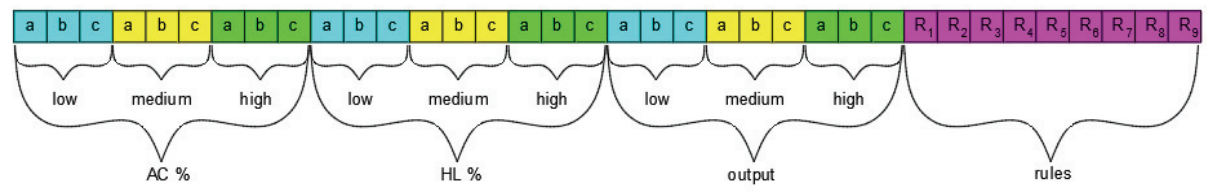

Figure 10 - Chromosome model used in the genetic algorithm

Each generation of the GA is comprised of 200 individuals. Root mean square error (RMSE) between the experiment results and the FL is used as the fitness function:

$R M S E=\sqrt{\frac{1}{n} \sum_{i=1}^{n}\left(y_{i}-o_{i}\right)^{2}}$

Here, $\mathrm{n}$ represents the number of data (individuals), $\mathrm{y}_{\mathrm{i}}$ represents the experiment result and $\mathrm{o}_{\mathrm{i}}$ represents the outputs of the FL model. Selection of individuals is made by the fitness proportionate selection method. In order to use fitness proportionate selection, solutions having a lower RMSE value should provide a higher fitness value. For this 
reason, the fitness value of each chromosome is updated by subtracting it from the highest fitness value of the relevant generation. Afterwards, cumulative fitness values are obtained by adding the fitness value of every previous individual onto the value of the current one. The cumulative fitness values are scaled between 0 and 1 by dividing each cumulative fitness value by the sum of all fitness values. Afterwards, the algorithm generates a random value between 0 and 1 and the first individual that has a greater cumulative fitness value than the random value generated is selected as a parent individual. The selection process is completed after selecting 198 parent individuals. Any individual can be selected more than once in this method.

Once the selection phase is completed, cross-over is applied to each parent individual with the probability of $\mathrm{P}(\mathrm{C})=1$. This means that each parent mates and crosses over with another (or sometimes the same) individual. In the cross-over process, each mating parent individual is cut from a random point and the values at the right hand side of the cutting point is swapped. Thus, two new individuals are formed. In order not to produce individuals having infeasible solutions, the condition $\mathrm{a}<\mathrm{b}<\mathrm{c}$ is checked, each representing the start, peak and end points of the triangular membership function as seen in Figure 2. If this condition is not fulfilled, $b$ is changed randomly between the values of $\mathrm{a}$ and $\mathrm{c}$.

Mutation is applied on each gene of the 198 new individuals with the probability of $\mathrm{P}(\mathrm{M})$ $=0.001$ upon completion of the cross-over phase. If the random value between 0 and 1 , generated for each gene by the algorithm, is smaller than 0.001 , then the value of the gene is changed randomly. The $\mathrm{a}<\mathrm{b}<\mathrm{c}$ condition is checked again if the mutation is applied. Afterwards, the 2 best individuals of the previous generation, which have the best fitness values, are copied into the relevant generation in an elitist way to complete a step of the GA. The aforementioned steps are repeated 1000 times before termination of the algorithm.

Upon termination of the GA, a local search method that looks for better solutions (individuals) around the best solution obtained, is applied. In this method, the value of each gene of the best individual is changed with small margins to check whether the fitness function provides a better solution or not. If a lower RMSE value is obtained, the search continues, or else the value of the next gene is changed. If none of the 36 genes provides a better solution, the local search is finalized.

The performance of the GA is affected by the initial values that are generated randomly, as well as the selected parameters. For this reason, each GA developed was run 10 times and the best values obtained were used as the triangular membership functions and rule base of the FL model. Flowchart of the FL model is given in Figure 11.

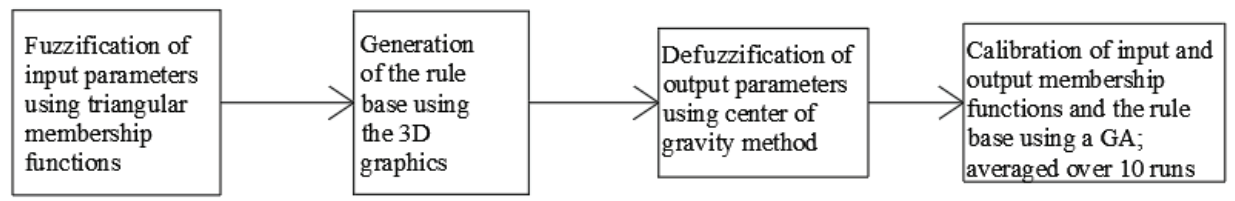

Figure 11 - Flowchart of the fuzzy logic model 


\section{ANN MODEL}

Contrary to FL models, ANN is a single network structure, using AC and HL values as input parameters to estimate Dp, VMA, MS, Va, F, VMA and MQ. The number of hidden layers and the number of neurons in each hidden layer were determined using the trial-error method. The best network performance was obtained using 20 neurons in a single hidden layer. The ANN model used is shown in Figure 12. In order to increase the performance of the ANN model, all input and output parameters were scaled between 0.1 and 0.9 as seen in Eq. 4 .

$x_{n}=\frac{\left(x_{n}-x_{\min }\right) * 0.8}{\left(x_{\max }-x_{\min }\right)}+0.1$

Here, $x_{n}$ represents the input or output value to be scaled, and $x_{\min }$ and $x_{\max }$ represent the minimum and the maximum values of this parameter in the data set, respectively. Sigmoid function (Eq. 5) is used as the activation function of both the hidden and the output layers. Thus, the output layer of each neuron was scaled between 0 and 1 .

$F(x)=\frac{1}{1+e^{-x}}$

Of the data with 90 varying AC from the Marshall design with 15 different HL content, 70\% were randomly assigned to the training set, $15 \%$ to the validation set and $15 \%$ to the test set. Gradient descent with momentum method was used in the training of the ANN model developed. Since the ANN model contains 7 different output parameters, the sum of the RMSE of each parameter was selected as the function to be minimized. In this way, all output parameters were optimized simultaneously. The flowchart of the ANN model is given in Figure 13.

The performance of both the FL and ANN models was also tested using the test results of 45 samples having optimum AC. Both FL and ANN models were developed using MATLAB R2017b ${ }^{\circledR}$ software and Fuzzy Logic and Neural Network toolboxes.

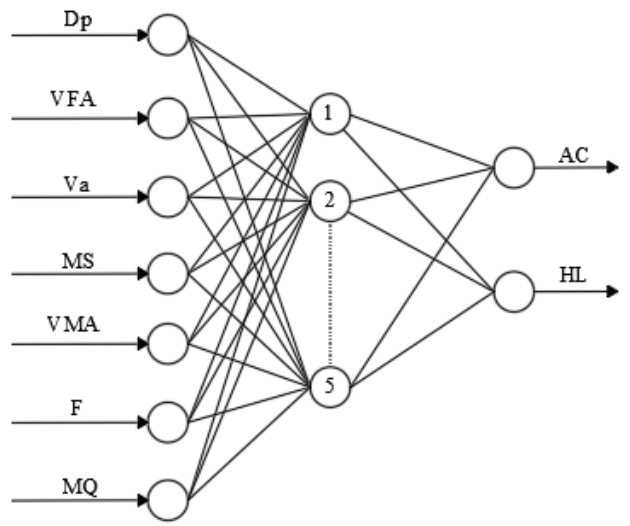

Figure 12 - Proposed ANN model 


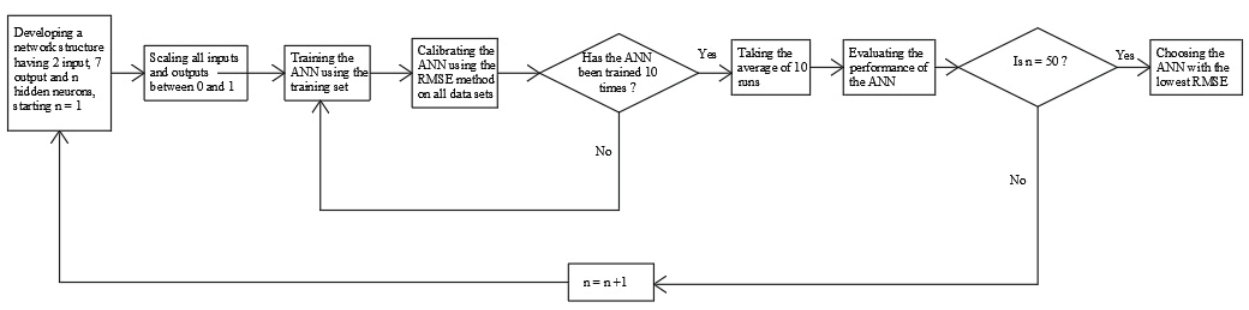

Figure 13 - Flowchart of the ANN model

\section{RESULTS AND DISCUSSIONS}

In this study, the change of hot mix asphalt properties obtained by the addition of HL into the mixture in a wide and precise range was investigated. In this context, 15 Marshall designs were prepared with HL content varying between $0.5 \%$ and $6.8 \%$ including a sample without any $\mathrm{HL}$ additive. In addition to the 270 samples in these designs, 45 control product samples were produced. Marshall test results, performed within the scope of the study, showed that the change of $\mathrm{HL}$ and $\mathrm{AC}$ content in the mixtures affects the Marshall design parameters. These effects can be summarized as follows:

When the relation between AC-HL ratios and Dp or VFA is examined, Dp and VFA decrease as the HL ratio increases and Dp and VFA increase as the AC ratio increases. In other words, while the ratio of $\mathrm{HL}$ is high and the rate of $\mathrm{AC}$ is low, Dp and VFA are low and vice versa.

The specific gravity of the HL is lower than that of the mineral filler, thus reducing the specific gravity of the total filler (Mineral filler $+\mathrm{HL}$ ) in the mixture and also the practical specific gravity of the mixture (Table 4, Figure 14). Thus, as the amount of HL increases, the mixture gains a structure with more voids (Table 4, Figure 15). Although the aggregate mixture in the study is dense, in other words well-graded, this condition continues to be observed due to the low density of the HL.

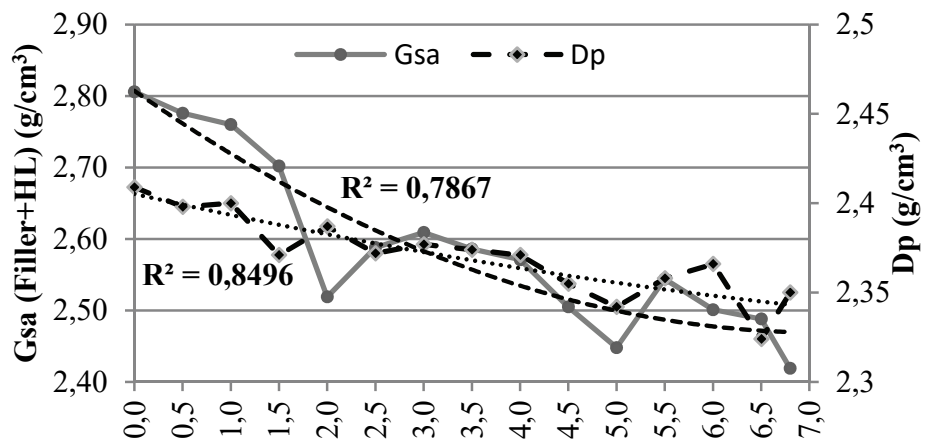

HL (\%)

Figure 14 - Reduction effect of HL on specific gravity of filler mix and Dp 


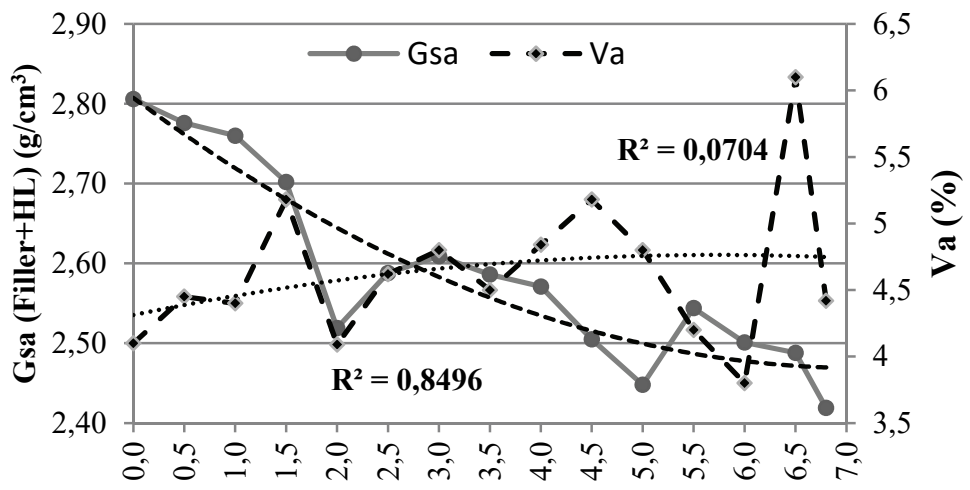

HL (\%)

Figure 15 - Effect of HL on air voids and specific gravity of filler mix

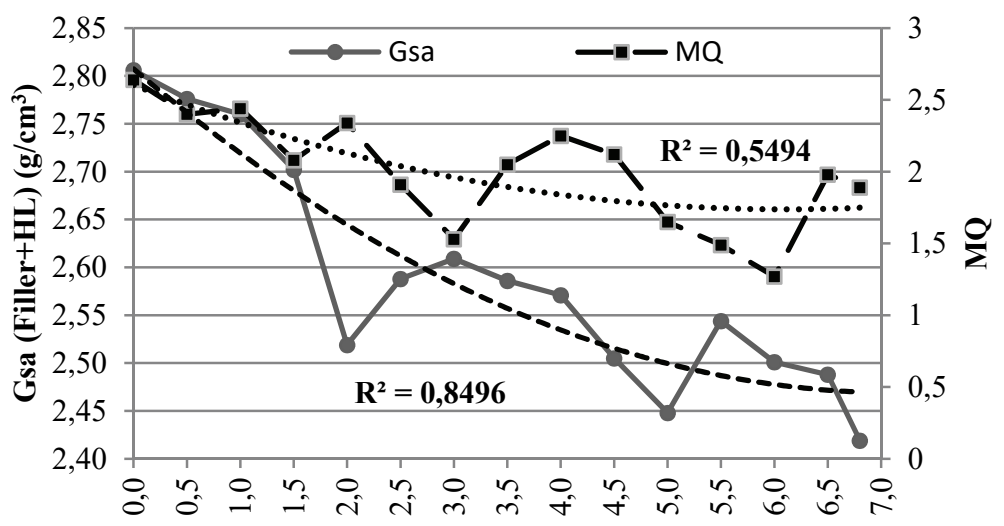

HL (\%)

Figure 16 - Effect of HL on $M Q$ and specific gravity of filler mix

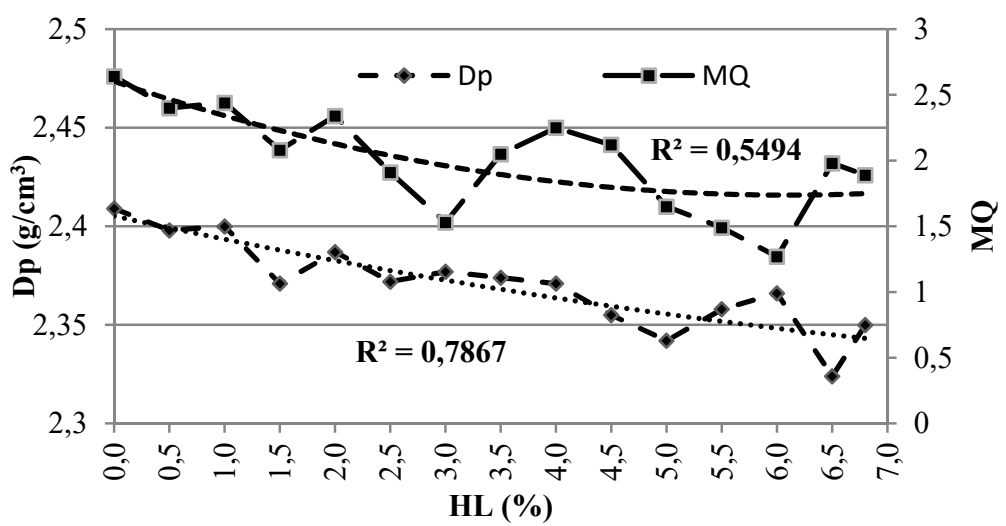

Figure 17 - Effect of HL on MQ and practical specific weight of specimen 


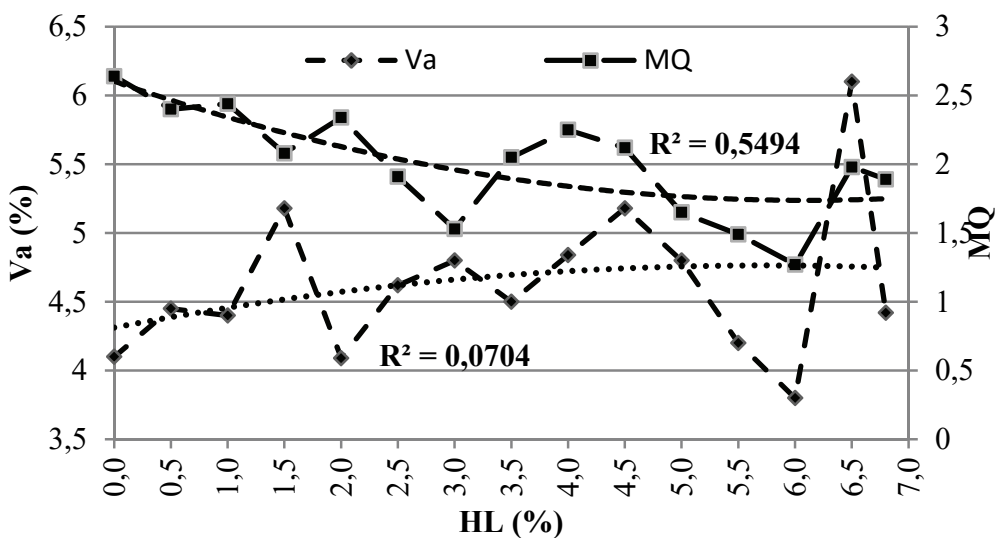

Figure 18 - Effect of HL on MQ and air voids

As is well-known, MQ is used as a measure of the rigidity of the mixture and its resistance to deformation. MQ helps to evaluate the deformation strength of the asphalt specimens produced and shows the fractural strengths of the mixtures during displacement. In this respect, it can be said that mixtures with higher MQ cause less displacement at the time of fracture. When the HL ratio increases in the mixtures, Gsa and Dp are reduced. In parallel, MQ also has a tendency to decrease in this context (Table 4, Figure 17). Similarly, in parallel with the increase in HL ratio, the decrease in MQ is observed when the air voids in the mixtures increase (Table 4, Figure 18).

When the relationship between AC-HL ratio and Va or VMA is examined, Va and VMA increase as the ratio of HL increases, and $\mathrm{Va}$ and VMA decrease as the AC ratio increases. That is, while the HL ratio is high and the AC ratio is low, Va and VMA are high and vice versa. When the HL is almost the same size as the mineral filler material and is a material with a high void ratio, then as the amount of HL in the mixture increases, the aggregate gradation is also affected and the total amount of voids increases. This increase causes a decrease in the MQ.

The HL ratio in the mixture can be evaluated differently from the other parameters for MS and $\mathrm{F}$. The highest MS values were obtained in the mixture where HL was used at $1 \%$. The increase in $\mathrm{AC}$ ratio decreases the MS value.

Testing of the results found by conventional methods using the models established with the help of soft computation methods guides the decisions in systematic control of the obtained data. This contributes to making the decision making processes more reliable and faster. Findings of the model comparisons obtained within the scope of the study can be summarized as follows:

In order to measure and compare the performances of the developed models, the determination coefficient $\left(\mathrm{R}^{2}\right)$, mean, and minimum and maximum error values were calculated for the model and test results. Table 6 shows the comparison between each model developed with the test results for 90 samples having various bitumen contents. Table 7 shows comparison of the results of each model developed with the test results for 15 samples having optimum bitumen content. 
Table 6 - Performance values of models for 90 samples having various bitumen contents

\begin{tabular}{|c|c|c|c|c|}
\hline Parameter & Performance criteria & $\begin{array}{l}\text { Mathematical } \\
\text { Model }\end{array}$ & FL & ANN \\
\hline \multirow{4}{*}{$\hat{a}$} & $\mathbf{R}^{2}$ & 0.9650 & 0.8842 & 0.9435 \\
\hline & Mean Error (\%) & 0.2563 & 0.4700 & 0.3168 \\
\hline & Maximum Error (\%) & 0.8515 & 1.3709 & 1.2787 \\
\hline & Minimum Error (\%) & 0.0053 & 0.0027 & 0.0079 \\
\hline \multirow{4}{*}{$\stackrel{x}{>}$} & $\mathbf{R}^{2}$ & 0.9945 & 0.9401 & 0.9799 \\
\hline & Mean Error (\%) & 1.0369 & 4.3433 & 2.0885 \\
\hline & Maximum Error (\%) & 6.1400 & 14.3738 & 8.5664 \\
\hline & Minimum Error (\%) & 0.0058 & 0.0309 & 0.0480 \\
\hline \multirow{4}{*}{$\sum_{\Sigma}^{\infty}$} & $\mathbf{R}^{2}$ & 0.9345 & 0.6611 & 0.7533 \\
\hline & Mean Error (\%) & 3.0333 & 7.3677 & 6.2303 \\
\hline & Maximum Error (\%) & 26.1047 & 26.3525 & 27.7899 \\
\hline & Minimum Error (\%) & 0.0005 & 0.1015 & 0.0850 \\
\hline \multirow{4}{*}{$\nu^{\pi}$} & (n) & 0.9914 & 0.8837 & 0.9699 \\
\hline & Mean Error (\%) & 3.1172 & 17.9592 & 7.5526 \\
\hline & Maximum Error (\%) & 18.2326 & 122.8118 & 46.8119 \\
\hline & Minimum Error (\%) & 0.0098 & 0.1519 & 0.0389 \\
\hline \multirow{4}{*}{} & $\mathbf{R}^{2}$ & 0.7607 & 0.6297 & 0.7121 \\
\hline & Mean Error (\%) & 7.6361 & 10.0912 & 8.7926 \\
\hline & Maximum Error (\%) & 88.7000 & 41.7493 & 37.8947 \\
\hline & Minimum Error (\%) & 0.1232 & 0.3837 & 0.0147 \\
\hline \multirow{4}{*}{$\sum_{j}^{\$}$} & $\mathbf{R}^{2}$ & 0.9226 & 0.8519 & 0.8205 \\
\hline & Mean Error (\%) & 1.1078 & 1.6149 & 1.7953 \\
\hline & Maximum Error (\%) & 4.7083 & 5.5784 & 8.8705 \\
\hline & Minimum Error (\%) & 0.0000 & 0.0002 & 0.0031 \\
\hline \multirow{4}{*}{$\stackrel{O}{\Sigma}$} & $\mathbf{R}^{2}$ & 0.8845 & 0.6694 & 0.8534 \\
\hline & Mean Error (\%) & 7.3088 & 13.7737 & 9.8347 \\
\hline & Maximum Error (\%) & 45.3700 & 63.4532 & 32.6505 \\
\hline & Minimum Error (\%) & 0.0518 & 0.1131 & 0.0565 \\
\hline
\end{tabular}


Modelling the Effects of Hydrated Lime Additives on Asphalt Mixtures by ...

Table 7 - Performance values of models for 15 samples having optimum bitumen content

\begin{tabular}{|c|c|c|c|c|}
\hline Parameter & Performance criteria & $\begin{array}{l}\text { Mathematical } \\
\text { Model }\end{array}$ & FL & $\mathbf{A N N}$ \\
\hline \multirow{4}{*}{$\hat{a}$} & $\mathbf{R}^{2}$ & 0.6063 & 0.6198 & 0.8162 \\
\hline & Mean Error (\%) & 0.6281 & 0.6273 & 0.2500 \\
\hline & Maximum Error (\%) & 1.4799 & 1.9223 & 0.6804 \\
\hline & Minimum Error (\%) & 0.0845 & 0.0387 & 0.0047 \\
\hline \multirow{4}{*}{$\mathbb{x}_{>}^{\mathbb{x}}$} & $\mathbf{R}^{2}$ & 0.6832 & 0.7175 & 0.8545 \\
\hline & Mean Error (\%) & 3.7188 & 5.0791 & 1.6780 \\
\hline & Maximum Error (\%) & 9.4724 & 11.2696 & 4.8664 \\
\hline & Minimum Error (\%) & 0.6364 & 0.8322 & 0.1908 \\
\hline \multirow{4}{*}{$\sum_{\Sigma}^{\infty}$} & $\mathbf{R}^{2}$ & 0.4855 & 0.2590 & 0.6292 \\
\hline & Mean Error (\%) & 7.1947 & 7.0599 & 5.8861 \\
\hline & Maximum Error (\%) & 30.4837 & 18.9283 & 20.2716 \\
\hline & Minimum Error (\%) & 0.0000 & 0.3913 & 0.0036 \\
\hline \multirow{4}{*}{$\nu^{\pi}$} & $\mathbf{R}^{2}$ & 0.4642 & 0.2519 & 0.7688 \\
\hline & Mean Error (\%) & 11.3209 & 14.8203 & 5.2815 \\
\hline & Maximum Error (\%) & 23.8579 & 35.9588 & 17.3608 \\
\hline & Minimum Error (\%) & 1.3333 & 3.0521 & 0.0173 \\
\hline \multirow{4}{*}{ 工 } & $\mathbf{R}^{2}$ & 0.0001 & 0.0324 & 0.5499 \\
\hline & Mean Error (\%) & 16.3220 & 14.8838 & 7.6077 \\
\hline & Maximum Error (\%) & 56.7358 & 33.0518 & 18.2677 \\
\hline & Minimum Error (\%) & 1.8692 & 1.8841 & 0.7264 \\
\hline \multirow{4}{*}{ 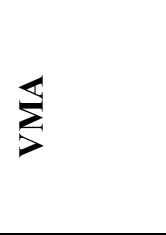 } & $\mathbf{R}^{2}$ & 0.6465 & 0.5000 & 0.7164 \\
\hline & Mean Error (\%) & 3.2171 & 3.0526 & 1.4261 \\
\hline & Maximum Error (\%) & 7.4559 & 6.9994 & 4.6335 \\
\hline & Minimum Error (\%) & 0.5335 & 0.6796 & 0.0101 \\
\hline \multirow{4}{*}{$\stackrel{O}{\Sigma}$} & $\mathbf{R}^{2}$ & 0.0308 & 0.0260 & 0.2753 \\
\hline & Mean Error (\%) & 16.7765 & 11.8207 & 9.7571 \\
\hline & Maximum Error (\%) & 52.3910 & 27.5497 & 25.1477 \\
\hline & Minimum Error (\%) & 0.5990 & 0.7054 & 0.2724 \\
\hline
\end{tabular}


According to Table 6, it is seen that ANN provides better results in estimating the Marshall design parameters than the FL and ANN models. This is an expected outcome since the mathematical model was developed to give the best result for the provided samples. According to Table 7, the performance of the mathematical model is the lowest compared to the FL and ANN models in terms of $\mathrm{R}^{2}$ and error values. This shows that the mathematical model performs well only for its own data set and is not suitable for generalization. It can be seen that the FL model, like the mathematical model, is not very successful in predicting the values of the samples having optimum bitumen content. The generalization performance of the ANN model is the best amongst the three models developed.

The low generalization performance of the mathematical model indicates that the superstructure designs made using this calculation method cannot show the expected performance and may encounter different types of deformations before the end of their desired service life. The FL model also fails to provide satisfactory performance in estimating the Marshall design parameters. The main reason for this low performance may be that the developed model is kept as simple as possible. For example, expressing each input and output value with more than 3 classes could significantly increase the model performance.

However, the identification of too many classes will cause the model to become unnecessarily complicated and may reduce the ability to generalize. It is seen that the ANN model can estimate the Dp, VFA and Va of the samples more accurately than the remaining parameters. Nevertheless, the overall performance of the ANN model is lower when compared with similar studies [40, 43, 44, 47, 59] in the literature. In this study, for the MS values of 90 samples with AC and 15 samples with optimum AC, the correlation coefficients between the test results and ANN model results were 0.7533 and 0.6292 , respectively, while [40] obtained these results as 0.969 and 0.933. In [44], the coefficients of correlation between the test results of polypropylene-modified Marshall samples and the ANN model were 0.97, 0.81 and 0.87 for MS, F and MQ, respectively; in this study, the coefficients for 90 samples were $0.7533,0.7121$ and 0.8534 and for the 15 samples were $0.6292,0.5499$ and 0.2753 , respectively. The test data were obtained from the re-creep test results applied on the polypropylene modified Marshall samples in [43]; on the SBS modified bitumen in [47]; and from the test results of permanent deformations on asphalt-concrete mixtures modified with nano additives in [59]. All 3 studies obtained high correlation coefficients $\left(R^{2}>0.90\right)$ between the test and ANN model results. In this study, such high coefficients were obtained only for the Dp, VFA and Va values of the 90 samples with different AC.

Between the two different models developed within the scope of the study, the ANN model provides better results. However, the $\mathrm{R}^{2}$ values obtained with the estimations made by this model gave lower predictive values for some parameters (MS, F) while providing better estimates for the remaining parameters compared to [60] on the estimation of the Marshall parameters of bituminous mixtures using artificial intelligence techniques. One of the reasons for this performance is the attempt to estimate seven different parameters using only two input values, AC and HL. There may be different factors that affect each of these seven parameters. Determination of these factors and incorporation of them into the model could lead to much better performance values. Another reason is the possibility of measurement errors in the samples in the laboratory tests. When looking at the data in this light, then for example, a flow rate of $6.52 \mathrm{~mm}$ (Table 4) appears to be an extremely high value. When these measurement errors are eliminated, the performance of the models can also increase 
significantly. In addition, the presence of only limited samples with the optimum bitumen content is another reason why the performance, especially the $\mathrm{R}^{2}$ value, is low. Also, more samples having optimum bitumen content for different HL contents can be developed and tested in order to improve the performance of the models. It shall be noted that the prediction performance of the models is valid only for the given data set. As the data set increases with experiments carried out using different materials, the superiority of one model over another may also change.

\section{CONCLUSIONS}

In this study, the effect of the use of HL as an additive in asphalt mixtures on the Marshall parameters was investigated and it was observed that the use of additive materials changes the properties of the mixture and also depends on the AC ratio. In general, it is possible to say that Dp and VFA values decrease and Va and VMA values increase due to an increase in $\mathrm{HL}$ ratio. When the relationship between $\mathrm{HL}$ and $\mathrm{AC}$ is evaluated, it is possible to say that due to the porous structure of the HL, as its usage rate in the mixtures increases, the AC ratio that has to be used in the mixtures also increase. In addition, the highest MS values from the experimental results were found to be obtained for $1 \% \mathrm{HL}$ usage rate, also depending on the $\mathrm{AC}$ content, and the yield values in the relevant ratio were found to be acceptable.

Estimating the properties of asphalt samples with HL additive by using artificial intelligence methods is a rather simple, fast and inexpensive solution compared to making laboratory tests on each sample. This study shows that a model developed using preliminary test results can be used to estimate the Marshall design parameters such as Dp, VMA, Va, MS, VFA, F and MQ of asphalt samples. Naturally, since the developed models have been calibrated for certain materials, they will work well for mixtures prepared by using the materials obtained from the same source and having the same material properties. If the material properties change, a re-calibration process will be required. Once this calibration is done, the models will be able to produce effective results for every mixture of materials having the same feature. Various specifications indicate the upper and lower limit values for the Marshall design parameters of the asphalt samples. Using advanced artificial intelligence methods, designs with different $\mathrm{AC}$ and $\mathrm{HL}$ values can be checked as to whether they meet the specified limits or not, without further need for laboratory tests. In addition, the models can be further developed to determine the asphalt mixture having the lowest cost that will meet the required ranges in the specifications.

\section{Symbols}

a : Start point of a membership function

b : Midpoint of a membership function

c : Endpoint of a membership function

Dp : Unit weight (practical specific weight) $\left(\mathrm{g} / \mathrm{cm}^{3}\right)$

$\mathrm{F} \quad$ : Flow rate $(\mathrm{mm})$

$\mathrm{F}(\mathrm{x}) \quad$ : Sigmoid activation function 
Gsa : Apparent specific gravity of mineral filler and HL mixture $\left(\mathrm{g} / \mathrm{cm}^{3}\right)$

MS : Marshall Stability $(\mathrm{kN})$

MQ : Marshall Quotient (MS/F)

$\mathrm{n} \quad$ : Number of values in the data set

$\mathrm{O}_{\mathrm{i}} \quad$ : Output values of the FL model

$\mathrm{P}(\mathrm{C}) \quad$ : Cross-over probability

$\mathrm{P}(\mathrm{M}) \quad$ : Mutation probability

$\mathrm{R} \quad$ : Rules defined in the rule base of the FL model

$\mathrm{Va} \quad$ : Air voids (\%)

VFA : Void filled with asphalt (\%)

VMA : Voids in mineral aggregate (\%)

$\mathrm{X}_{\max } \quad$ : Maximum value of parameter $\mathrm{x}$

$\mathrm{x}_{\min } \quad$ : Minimum value of parameter $\mathrm{x}$

$\mathrm{X}_{\mathrm{n}} \quad$ : Input or output parameter $\mathrm{x}$

$\overline{\mathrm{x}}_{\mathrm{o}} \quad$ : Projection of the membership function on the horizontal axis

$\mu_{\mathrm{A}} \quad$ : Membership function of $\mathrm{A}$

\section{Acknowledgments}

The authors would like to thank YTU BAP Coordination Unit for their support for the Research Project with ID 29-05-01-KAP01 and also Isfalt A.Ş. for their support with the experiments.

\section{References}

[1] NLA, Hydrated Lime - A Solution for High Performance Hot Mix Asphalt. Retrieved January 8, 2016, from http://www.lime.org/documents/publications/free_downloads/ fact-asphalt.pdf

[2] Lesueur, D., Hydrated Lime: a Proven Additive for Durable Asphalt Pavements Critical Literature Review, European Lime Association (EuLA) Ed., 2010, Brussels, Belgium, 2010.

[3] TSE, Turkish Standard 3720: Bituminous mixtures - Asphalt concrete - Mix design Marshall method, 2010.

[4] Asphalt Institute, The Asphalt Handbook (MS-4), 7th. ed., Asphalt Institute: Lexington, 2007. 
[5] Witczak, M., Bari, J., Development of a master curve ( $\left.\mathrm{E}^{*}\right)$ database for lime modified asphaltic mixtures. Arizona State University Research Report, Tempe (Arizona, USA): Arizona State University, (July) 2004.

[6] Lesueur, D., Little, D., Effect of Hydrated Lime on Rheology, Fracture, and Aging of Bitumen. Transportation Research Record: Journal of the Transportation Research Board, 1661(-1), 93-105, 1999.

[7] Petersen, J. C., Plancher, H., Harnsberger, P. M., Lime Treatment of Asphalt to Reduce Age Hardening and Improve Flow Properties. Association of Asphalt Paving Technologists, 56-87, 632-653, 1987.

[8] Cross, S., Experimental Cold In-Place Recycling with Hydrated Lime. Transportation Research Record, 1684(1), 186-193, 1999.

[9] Sebaaly, P., Hitti, E., Weitzel, D., Effectiveness of Lime in Hot-Mix Asphalt Pavements. Transportation Research Record, 1832(1), 34-41, 2003.

[10] Lee, S., Seo, Y., Kim, Y. R., Effect of hydrated lime on dynamic modulus of asphaltaggregate mixtures in the state of North Carolina. KSCE Journal of Civil Engineering, 14(6), 829-837, 2010.

[11] Niazi, Y., Jalili, M., Effect of Portland cement and lime additives on properties of cold in-place recycled mixtures with asphalt emulsion. Construction and Building Materials, 23(3), 1338-1343, 2009.

[12] Rogge, D. F., Leahy, R. B., Blair, R., Cold-In-Place (CIP) Recycling with Lime. Transportation Research Report, 95-17, 1995.

[13] Al-Suhaibani, A. R., Al-Mudaiheem, J., Al-Fozan, F., Effect of Filler Type and Content on Properties of Asphalt Concrete Mixes. In Effects of Aggregates and Mineral Fillers on Asphalt Mixtures Performance, 107-130, 1992.

[14] Niazi, Y., Jalili, M., Effect of Portland cement and lime additives on properties of cold in-place recycled mixtures with asphalt emulsion. In Construction and Building Materials 23(3):1338-1343, 2009.

[15] Lesueur, D., Little, D., Hydrated Lime as an Active Filler in Bitumen. Paper Presented at the Annual Meeting of the TRB, Washington, D.C., January 1999.

[16] Mohammad, L., Abadie, C., Gokmen, R., Puppala, A., Mechanistic Evaluation of Hydrated Lime in Hot-Mix Asphalt Mixtures. Transportation Research Record, 1723(1), 26-36, 2000.

[17] Kennedy, T. W., Ping, W. V., An Evaluation Of Effectiveness Of Antistripping Additives In Protecting Asphalt Mixtures From Moisture Damage (With Discussion) (pp. 230-263). Washington: Association of Asphalt Paving Technologists, 1991.

[18] Si, Z., Little, D. N., Asce, F., Lytton, R. L. (2002). Effects of Inorganic and Polymer Filler on Tertiary Damage Development in Asphalt Mixtures, (April), 164-172.

[19] Huang, S.-C., Claine Petersen, J., Robertson, R., Branthaver, J., Effect of Hydrated Lime on Long-Term Oxidative Aging Characteristics of Asphalt. Transportation Research Record, 1810(307), 17-24, 2002. 
[20] Radenberg, M., Effect of Hydrated Lime Addition on the Deformation of Hot Mix Asphalt in the Wheel Tracking Test. In Lhoist HMA Symposium. Düsseldorf, 1998.

[21] Rogge, D. F., Leahy, R. B. and Blair, R., Cold In-Place (CIP) Recycling with Lime. Transportation Research Instit., OR State Univ, Corvallis, OR, July 1995.

[22] Şengül, C. E., Asfalt Kaplamalarda Tekerlek İzinde Oturma ve Su Hasarı Problemlerinin Azaltılması İçin Sönmüş Kireç Kullanımı. Karadeniz Technical University, 2006.

[23] Verhasselt, A. F., Choquet, F. S., Comparing Field And Laboratory Aging Of Bitumens On A Kinetic Basis. Transportation Research Record, 30-38, 1993.

[24] Hicks, R. G., Moisture Damage in Asphalt Concrete. Washington: NCHRP Transportation Research Board, 1991.

[25] Kennedy, T. W., Ping, W. V., Evaluation of Effectiveness of Antistripping Additives in Protecting Asphalt Mixtures from Moisture Damage. Journal of the Association of Asphalt Paving Technologists, from the Proceedings of Technical Sessions, Vol. 60, March 1991.

[26] Little, D. N., Epps, J. A., The Benefits of Hydrated Lime in Hot Mix Asphalt. Arlington, 2001.

[27] Petersen, J.C., Plancher, H., and Harnsberger, P.M., Lime Treatment of Asphalt to Reduce Age Hardening and Improve Flow Properties. AAPT, Volume 56, 1987.

[28] Sebaaly, P.E., Tohme, P., Hitti, E., Stansburry, K., Epps, J., Asphalt Concrete Antistripping Techniques, Pierre, 2003.

[29] Rogge, D. F., Leahy, R. B. and Blair, R., Cold In-Place (CIP) Recycling with Lime, Transportation Research Instit., OR State Univ, Corvallis, OR, July 1995.

[30] Jones, G. M., The Effect of Hydrated Lime on Asphalt in Bituminous Pavements. NLA Meeting, Utah DOT, May 22, 1997.

[31] Kim, Y. R., Little, D. N., Song, I., Effect of Mineral Fillers on Fatigue Resistance and Fundamental Material Characteristics. Transportation Research Record, (1832), 1-8, 2003.

[32] Recasens, R. M., Martinez, A., Jimenez, F. P., Bianchetto, H., Effect of Filler on the Aging Potential of Asphalt Mixtures. Transportation Research Board, (1901), 10-17, 2005.

[33] Cheng, D. X., Little, D. N., Lytton, R. L., Holste, J. C., Moisture Damage Evaluation of Asphalt Mixture by Considering Both Moisture Diffusion and Repeated Load Conditions. Transportation Research Board, (1832), 42-49, 2003.

[34] Hicks, R. G., Todd, V. S., Life Cycle Costs for Lime in Hot Mix Asphalt, 2001. Retrieved January 11, 2016, from https://ime.org/documents/publications/ free_downloads/lcca_vol-2.pdf

[35] Yardım, M. S., Balcı, U., The Effect of Hydrated Lime on the Marshall Stability for a Specific Amount of Asphalt Content in the Hot Mix Asphalt, Proceedings of the 9th International Fracture Conference, 9th International Fracture Conference, pp. 571-580. Yıldız Technical University, Istanbul, 2011. 
[36] Tigdemir, M., Karasahin, M., Sen, Z., Investigation of fatigue behaviour of asphalt concrete pavements with fuzzy-logic approach. International Journal of Fatigue, 24(8), 903-910, 2002.

[37] Saltan, M., Saltan, S., Şahiner, A., Fuzzy logic modeling of deflection behavior against dynamic loading in flexible pavements. Construction and Building Materials, 21(7), 1406-1414, 2007.

[38] Saltan, M. Sezgin, H., Hybrid neural network and finite element modeling of sub-base layer material properties in flexible pavements. Materials and Design, 28, 1725-1730, 2007.

[39] Ozsahin, T.H., Oruc, S., Neural network model for resilient modulus of emulsified asphalt mixtures. Construction and Building Materials, 22, 1436-1445, 2008.

[40] Ozgan, E., Artificial neural network based modelling of the Marshall Stability of asphalt concrete. Expert Systems with Applications, 38(5), 6025-6030, 2011.

[41] Xiao, F., Amirkhanian, S. N., Juang, C. H., Hu, S., Shen, J., Model developments of longterm aged asphalt binders. Construction and Building Materials, 37, 248-256, 2012.

[42] Mirzahosseini, M. R., Aghaeifar, A., Alavi, A. H., Gandomi, A. H., Seyednour, R., Permanent deformation analysis of asphalt mixtures using soft computing techniques. Expert Systems with Applications, 38(5), 6081-6100, 2011.

[43] Tapkin, S., Çevik, A., Uşar, Ü., Accumulated strain prediction of polypropylene modified marshall specimens in repeated creep test using artificial neural networks. Expert Systems with Applications, 36, 11186-11197, 2009.

[44] Tapkin, S., Çevik, A., Uşar, Ü., Prediction of Marshall test results for polypropylene modified dense bituminous mixtures using neural networks. Expert Systems with Applications, 37, 4660-4670, 2010.

[45] Xiao, F., Amirkhanian, S. N., Artificial Neural Network Approach to Estimating Stiffness Behavior of Rubberized Asphalt Concrete Containing Reclaimed Asphalt Pavement. Journal of Transportation Engineering, 135(8), 580-589, 2009.

[46] Kok, B.V., Yilmaz, M., Sengoz, B., Sengur, A., Avci, E., Investigation of complex modulus of base and SBS modified bitumen with artificial neural networks. Expert Systems with Applications, 37, 7775-7780, 2010.

[47] Kok, B.V., Yilmaz, M., Cakiroglu, M., Kuloglu, N. Sengur, A., Neural network modeling of SBS modified bitumen produced with different methods. Fuel, 106, 265$270,2013$.

[48] Cevik, A., Cabalar, A.F., Modelling damping ratio and shear modulus of sand-mica mixtures using genetic programming. Expert Systems with Applications, 36, 7749$7757,2009$.

[49] Aksoy, A., Iskender, E., Kahraman, H.T., Application of the intuitive k-NN Estimator for prediction of the Marshall Test (ASTM D1559) results for asphalt mixtures. Construction and Building Materials, 34, 561-569, 2012. 
[50] Moghaddam, T.B., Shamshirband, S., Soltani, M., Petkovic, D., Karim, M.R. Baaj, H., Estimation of the rutting performance of Polyethylene Terephthalate modified asphalt mixtures by adaptive neuro-fuzzy methodology. Construction and Building Materials, 96, 550-555, 2015.

[51] Pourtahmasb, M. S., Karim, M.R. Shamshirband, S. Resilient modulus prediction of asphalt mixtures containing Recycled Concrete Aggregate using an adaptive neurofuzzy methodology. Construction and Building Materials, 82, 257-263, 2015.

[52] Kavak, A., Lime Stabilization in Turkey. In The Seminar of Lime in Asphalt. İstanbul: İsfalt, 2011.

[53] Denayer, C., Lime Stabilization. In The Seminar of Lime in Asphalt. İstanbul: İsfalt, 2011.

[54] Highway Technical Specifications, General Directorate of Highways, Item No. 170/2, Ankara, Turkey, 2006.

[55] ASTM D 6927-15, Standard Test Method for Marshall Stability and Flow of Bituminous Mixtures, 1-7, 2010.

[56] KGM, Karayolu Teknik Şartnamesi. Ankara: Karayolları Genel Müdürlüğü, 2006.

[57] Yardım, M. S., Gürsoy, M, Balcı, U., The Effect of Hydrated Lime Content Amount on Low Temperature Cracking Strength of Flexible Pavements for Various Temperature Values (in Turkish), YTÜ BAP Research Project, No. 29-05-01-KAP01, İstanbul, 2014.

[58] Wang, W.J., Luoh, L., Simple Computation of the Defuzzifications of Center of Sum and Center of Gravity," Journal of Intelligent and Fuzzy Systems (9) 1-2, pp. 53-59, 2000.

[59] Shafabakhsh, G.H., Jafari Ani, O., Talebsafa, M., Artificial neural network modeling (ANN) for predicting rutting performance of nano-modified hot-mix asphalt mixtures containing steel slag aggregates. Construction and Building Materials, 85, 136-143, 2015.

[60] Khuntia, S., Das, A.K., Mohanty M., Panda, M., Prediction of Marshall Parameters of Modified Bituminous Mixtures Using Artificial Intelligence Techniques. International Journal of Transportation Science and Technology, 3, 211-228, 2014. 
